\title{
Aspergilloma in Active Tuberculosis: A Case Report
}

Waseem Raja Dar*

Department of Internal Medicine, Pulmonology Department, Sheri Kashmir Institute of Medical Sciences, Soura, Jammu \& Kashmir, India

*Corresponding author: Waseem Raja Dar, Department of Internal Medicine, Pulmonology Department, Sheri Kashmir Institute of Medical Sciences, Soura, Jammu \& Kashmir, India, Tel: +91-8261815278; E-mail: drwaseem.mw@gmail.com

Rec date: Nov 03, 2015, Acc date: Dec 08, 2015, Pub date: Dec 15, 2015

Copyright: $\odot 2015$ Dar WR. This is an open-access article distributed under the terms of the Creative Commons Attribution License, which permits unrestricted use, distribution, and reproduction in any medium, provided the original author and source are credited.

\begin{abstract}
Pulmonary Aspergilloma is a saprophytic colonization of a lung cavity by Aspergillus spp most often by Aspergillus fumigatus. It is usually secondary i.e. it occurs in a pre-existing cavity often as a result of old healed pulmonary tuberculosis. Pulmonary Aspergilloma complicating active tuberculosis is rare. We report a case of sputum positive tuberculosis complicated by pulmonary Aspergilloma.
\end{abstract}

Keywords: Aspergilloma; Tuberculosis; Lobectomy

\section{Introduction}

Tuberculosis remains endemic in developing countries like India and causes significant morbidity and mortality. The affected lungs usually heal with fibrosis and cavities. Such cavities may provide a niche to fungi often resulting in formation of mycetomas. One such fungus is Aspergillus fumigatus and the resulting Aspergilloma may either be asymptomatic or sometimes present with fatal hemoptysis.

\section{Case Report}

A 55 year old male was admitted to the Department of Internal Medicine, Pulmonology Division with complaints of coughing of blood of three days duration. Each bout contained about 150-200 ml of red coloured blood. Patient had had history of productive cough and low grade fever for past 2 months for which he was evaluated and found to have sputum positive pulmonary tuberculosis. Patient was on ant tubercular treatment for past two months.

\begin{tabular}{|c|c|c|c|c|}
\hline Parameter & Result & Parameter & Result & \\
\hline $\mathrm{Hb}$ & $8.7 \mathrm{~g} \%$ & Urea & $28 \mathrm{mg} / \mathrm{dl}$ & \multirow{2}{*}{$\begin{array}{l}\text { ECG: Sinus } \\
\text { Tachycardia } \\
\text { Montaux Test: } \\
\text { Insignificant }\end{array}$} \\
\hline TLC & $8200 / \mathrm{mm} 3$ & Creatinine & $\begin{array}{l}1.3 \\
\mathrm{mg} / \mathrm{dl}\end{array}$ & \\
\hline DLC & $\begin{array}{l}\text { Neutros }=60 \% \\
\text { Lymphos }=35 \%\end{array}$ & Bilirubin & $\begin{array}{l}1.28 \\
\mathrm{mg} / \mathrm{dl}\end{array}$ & \multirow{3}{*}{$\begin{array}{l}\text { HIV Serology: } \\
\text { Negative } \\
\text { Line probe } \\
\text { assay: AFB } \\
\text { sensitive to } \\
\text { Isoniazid } \\
\text { Rifampicin }\end{array}$} \\
\hline PLT & 3 lacs $/ \mathrm{mm} 3$ & ALT & $45 \mathrm{U} / \mathrm{L}$ & \\
\hline MCV & $79 f \mathrm{~L}$ & AST & $39 \mathrm{U} / \mathrm{L}$ & \\
\hline $\mathrm{MCH}$ & 25.9 & ALP & $120 \mathrm{U} / \mathrm{L}$ & \multirow{3}{*}{$\begin{array}{l}\text { INR: } 1.32 \\
\text { aPTT: } 29\end{array}$} \\
\hline \multirow{2}{*}{ ESR } & \multirow{2}{*}{$45 \mathrm{~mm} / /^{\mathrm{st}}$ hour } & Total Protein & $6.76 \mathrm{~g} / \mathrm{dl}$ & \\
\hline & & Albumin & $3.3 \mathrm{~g} / \mathrm{dl}$ & \\
\hline
\end{tabular}

Table 1: Investigations.
On examination patient was conscious and oriented, hemodynamically stable with no lymphadenopathy or clubbing. Pallor was present but there was no jaundice, cyanosis or pretibial edema. Respiratory System examination revealed bronchial breathing in left infraclavicular area. Cardiovascular, Abdominal and Nervous System examinations were normal. Baseline blood investigations revealed mild anemia (Table 1).

$\mathrm{X}$-ray chest was suggestive of a cavitation in left upper zone with suspicion of a fungalball.

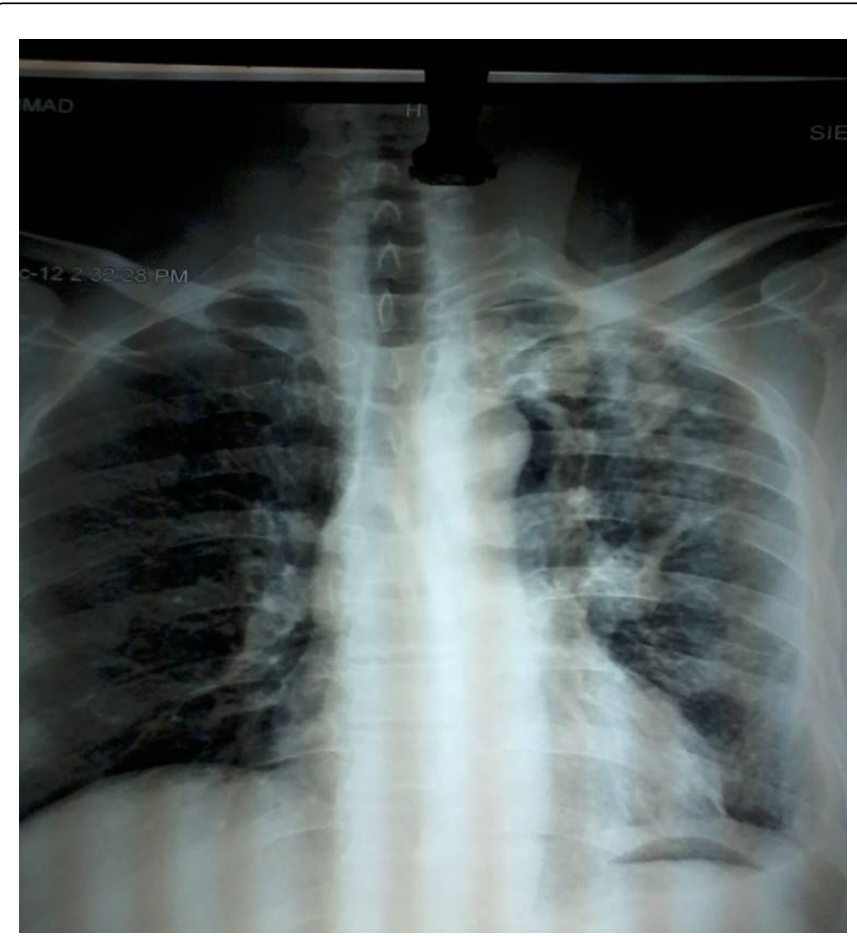

Figure 1: Left upper and middle zone fibrosis with cavitation in left upper zone with suspicious fungal ball.

CECT chest revealed left upper lobe multiple fibrotic areas with cavitation filled with sediment suggestive of Aspergilloma (Figure 2). 
Page 2 of 3

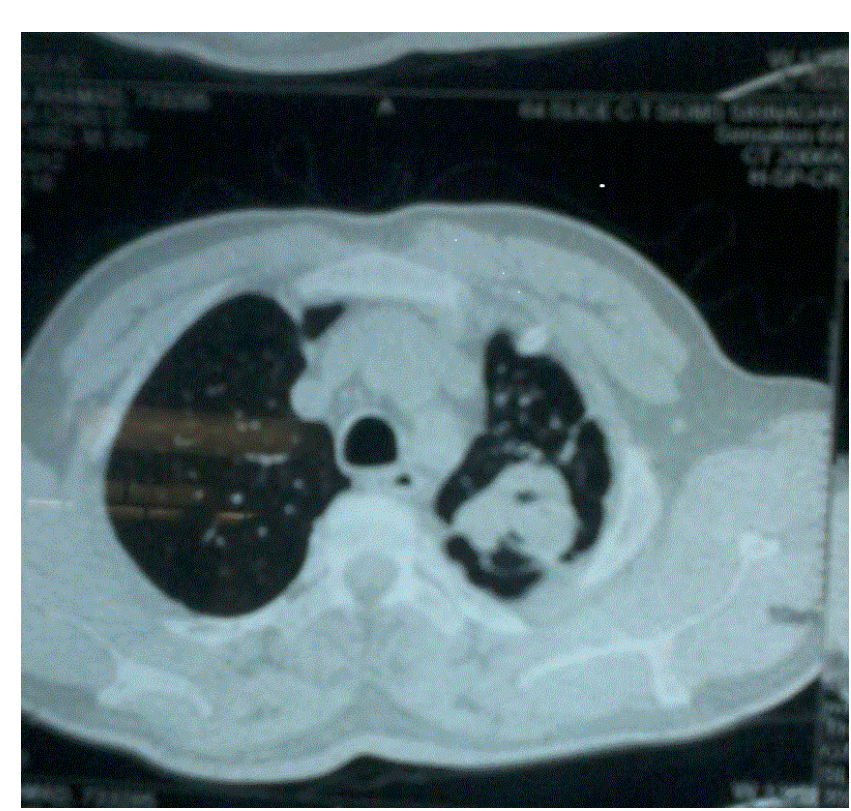

Figure 2: Left upper lobe multiple fibrotic areas with cavitation filled with sediment s/o Aspergilloma.

Sputum for AFB was positive twice. Our complete diagnosis was Active Cavitatory Pulmonary Tuberculosis with Aspergilloma. Patient underwent left upper lobectomy with peroperative findings of cavitation in left upper lobe with fungal ball (Figure 3).

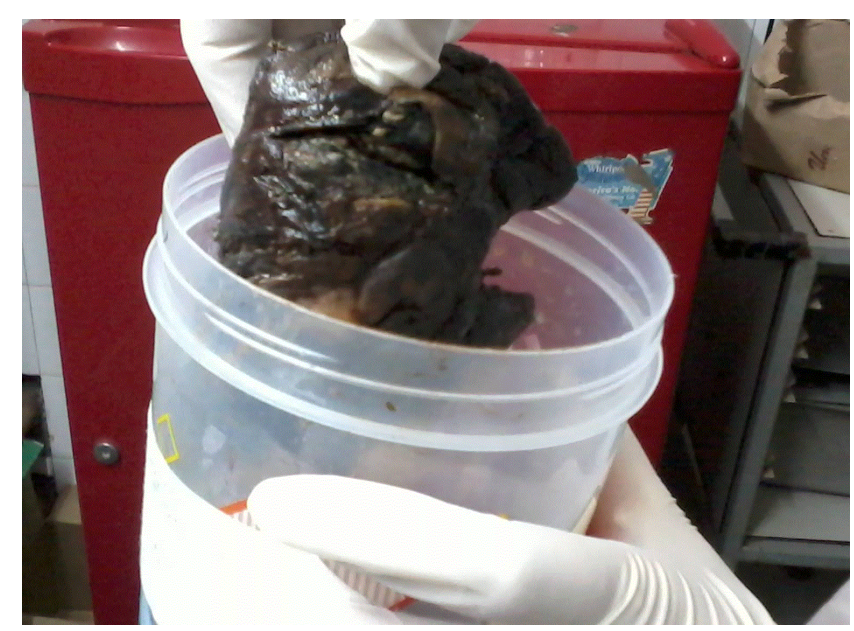

Figure 3: Surgical specimen showing fungal ball.

Patient was continued on intensive phase of antitubercular treatment for one more month and is presently on continuation phase of ATT. Sputum for AFB was negative after three months of intensive phase (i.e. one month post-surgery).

\section{Discussion}

Aspergillus fumigatus is the most common Aspergillus species that causes disease in humans $[1,2]$. The spectrum of Aspergillosis in humans ranges from a simple colonization to invasive infection. Hypersensitivity reactions may occur causing Allergic BronchopulmonaryAspergillosis (ABPA) while saprophytic growth may result in Aspergillomas. A fungus ball consists of both dead and living mycelial elements, fibrin, mucus, amorphous debris, and cellular elements. Aspergilloma is usually secondary i.e. occurs in a preexisting cavity due to tuberculosis etc. [3]. Primary Aspergilloma is rare [4]. Patients usually present with hemoptysis which may be life threatening with a mortality of $2-14 \%$. Diagnosis of pulmonary Aspergilloma is usually based on the clinical and radiographic features, combined with serological or microbiologic evidence of Aspergillus [5]. Chest radiographs reveal a solid round mass within a cavity partially surrounded by a radiolucent crescent (Monod's sign). Change in the position of the fungus ball after moving the patient on his side or from supine to prone position is another interesting but variable sign. CT chest also shows Monod sign i.e. crescent of air surrounding the fungal ball. Sputum cultures are positive only in $50 \%$ of cases. Serum precipitins are present in the sera of more than $95 \%$ of patients [6]. No treatment is required in asymptomatic cases. Symptomatic cases e.g. patients with hemoptysis may be treated with systemic or local administration of antifungal agents or surgical resection. Other treatment options include Bronchial artery embolization and cavernostomy.

Aspergilloma usually occurs in residual cavity caused by old tuberculosis $[7,8]$. Aspergillomas with active pulmonary tuberculosis (PTB) have rarely been reported [9]. The only largest series of Aspergilloma complicating active pulmonary tuberculosis was published by Ademeyo et al. They reviewed eleven cases of pulmonary Aspergilloma complicating active cavitating pulmonary tuberculosis. Nine of the 10 patients who had combined medical (Antituberculosis drugs) and surgical treatment were cured of their disease; one patient, who had bilateral multiple Aspergillomas, died from massive haemoptysis after resection of one of the affected lobes. The only medically treated patient who refused surgery had fatal haemoptysis at home. They recommended pulmonary resection for patients who are fit for operation [10]. Anita et al reported a case of Multidrug resistant tuberculosis co-existing with Aspergilloma and invasive Aspergillosis in a 50 year old diabetic woman that was successfully treated with pulmonary resection, Voriconazole and antitubercular therapy against MDR-TB.

\section{Conclusion}

Pulmonary Aspergilloma usually occurs in a pre-existing cavity, often due to old healed tuberculosis. Aspergilloma complicating active tuberculosis has rarely been reported. Pulmonary resection associated with antitubercular therapy is recommended in all cases.

\section{References}

1. Gefter WB (1992) The spectrum of pulmonary Aspergillosis. J Thorac Imaging 7: 56-74.

2. Vaideeswar P, Prasad S, Deshpande JR, Pandit SP (2004) Invasive pulmonary aspergillosis: A study of 39 cases at autopsy. J Postgrad Med 50: 21-26.

3. Martinez R, Castro GD, Machado AA, Moya MJ (2009) Primary aspergilloma and subacute invasive aspergillosis in two AIDS patients, Rev Inst Med Trop Sao Paulo 51: 49-52.

4. Glimp RA, Bayer AS (1983) Pulmonary aspergilloma. Diagnostic and therapeutic considerations. Arch Intern Med 143: 303-308. 
5. Pesle GD (1954) Monod O Bronchiectasis due to aspergilloma. Dis Chest 25: $172-183$.

6. Ueda H, Okabayashi K, Ondo K, Motohiro A (2001) Analysis of various treatments for pulmonary aspergillomas. Surg Today 31: 768-773.

7. Boghani AB, Patel MZ, Leuva AT, Patel BV, Patel NR, et al. (1987) Aspergilloma with active pulmonary tuberculosis. Indian J Tuberc 34: 206-207.

8. Urvinder PS, Pooja A, Aditi, Kalpesh P (2013) Co-existence of HIV, active tuberculosis and Aspergilloma in a single individual- a case report. Indian J Tuberc 60: 55-58.
9. Adeyemo AO, Edelowo EO, Makanjuola DJ (1984) Management of pulmonary aspergilloma in the presence of active tuberculosis. Thorax 39: 862-867.

10. Kumar AA, Shantha GPS, Jeyachandran V, Rajkumar K, Natesan S, et al (2008), Multidrug resistant tuberculosis co-existing with aspergilloma and invasive aspergillosis in a 50 year old diabetic woman: a case report. Cases Journal 1: 3031757-1626-1-303. 